\title{
Beyond ecological modelling: ground-truthing connectivity conservation networks through a design charrette in Western Australia
}

\author{
Simon Kilbane ${ }^{\mathrm{a}, *}$, Richard Weller ${ }^{\mathrm{b}}$, Richard Hobbs ${ }^{\mathrm{c}}$ \\ ${ }^{a}$ Faculty of Design, Architecture and Building, University of Technology Sydney, Australia \\ b School of Design, University of Pennsylvania, United States \\ ${ }^{c}$ School of Plant Biology, University of Western Australia, Australia
}

\section{ART ICLE INFO}

\section{Keywords:}

Connectivity conservation

Green infrastructure

Landscape architecture

Design charrette

Ecological planning

Australia

\begin{abstract}
A B S T R A C T
Globally, connectivity conservation projects exist across all inhabited continents. Typically created through Geographical Information Systems and modelling processes at regional and even continental scales, these projects are seldom evaluated or 'ground-truthed' for their potential application at the local level where land use is fully allocated and replete with human occupation. This article reviews the accuracy of one such continental-scale connectivity conservation network, the National Green Network, through assessment and redesign by a design charrette at the local scale in York, Western Australia. Breaking with traditional process, this research considered the National Green Network model not as a final plan, but as point of departure for an iterative adjustment and redesign process through the charrette and an additional detailed design stage. Commonplace in architecture and urban planning disciplines, the application of charrettes to connectivity conservation design offers the benefits of improving design accuracy and enhancing their potential for implementation through providing valuable feedback and iterative design adjustment. The fine-tuning conducted by this research enabled the design to factor in human land-uses and influences across complex landscapes, while considering in a critical manner cultural factors that could also influence the system's design and its success. The framing of the network as green infrastructure rather than as connectivity conservation in addition to further illustration by the landscape architect provided a spectrum of both ecological and cultural outcomes across the case study landscape, demonstrating potential impacts and opportunities offered through a series of spatially accurate and ground-truthed plans.
\end{abstract}

\section{Introduction}

The National Green Network (NGN) is a continental-scale green infrastructure research project conceived to counteract multiple contemporary environmental issues and to articulate environmental policies otherwise unexplored in a spatial sense across the Australian continent (Kilbane, 2013). The NGN proposed an ecologically robust and interconnected protected area network achieved through typical Geographical Information Systems (GIS) and ecological modelling software. The NGN offers a blueprint to address deforestation, ecological fragmentation and species extinction as well as the Australian-specific challenges of erosion and dryland salinity. It aims to strengthen the nation's landscape health, the resilience of its biota and ultimately the future of the Australian people who rely on this landscape.
Spanning the Australian continent, the NGN embraces two specific objectives that currently lack clear spatial articulation (Fig. 1). The first of these is the Convention on Biological Diversity (CBD) 'Aichi Targets' (United Nations, 2010b) of which Target 11 mandates that 'by 2020 , at least 17 per cent of terrestrial and inland water areas and 10 per cent of coastal and marine areas, especially areas of particular importance for biodiversity and ecosystem services, are conserved through effectively and equitably managed, ecologically representative, and well-connected systems of protected areas' (United Nations, 2010a). This motivation is reflected by similar Australian policies aimed at halting biodiversity loss, safeguarding ecosystems and protecting species and genetic diversity, namely through the protected network of the National Reserve System (NRS) and its similar percentage-based

\footnotetext{
* Corresponding author at: University of Technology Sydney, PO Box 123, Broadway, NSW 2007, Australia.

Email addresses: simon.kilbane@uts.edu.au, simonkilbane@gmail.com (S. Kilbane); rjweller@design.upenn.edu (R. Weller); richard.hobbs@uwa.edu.au (R. Hobbs)
} 


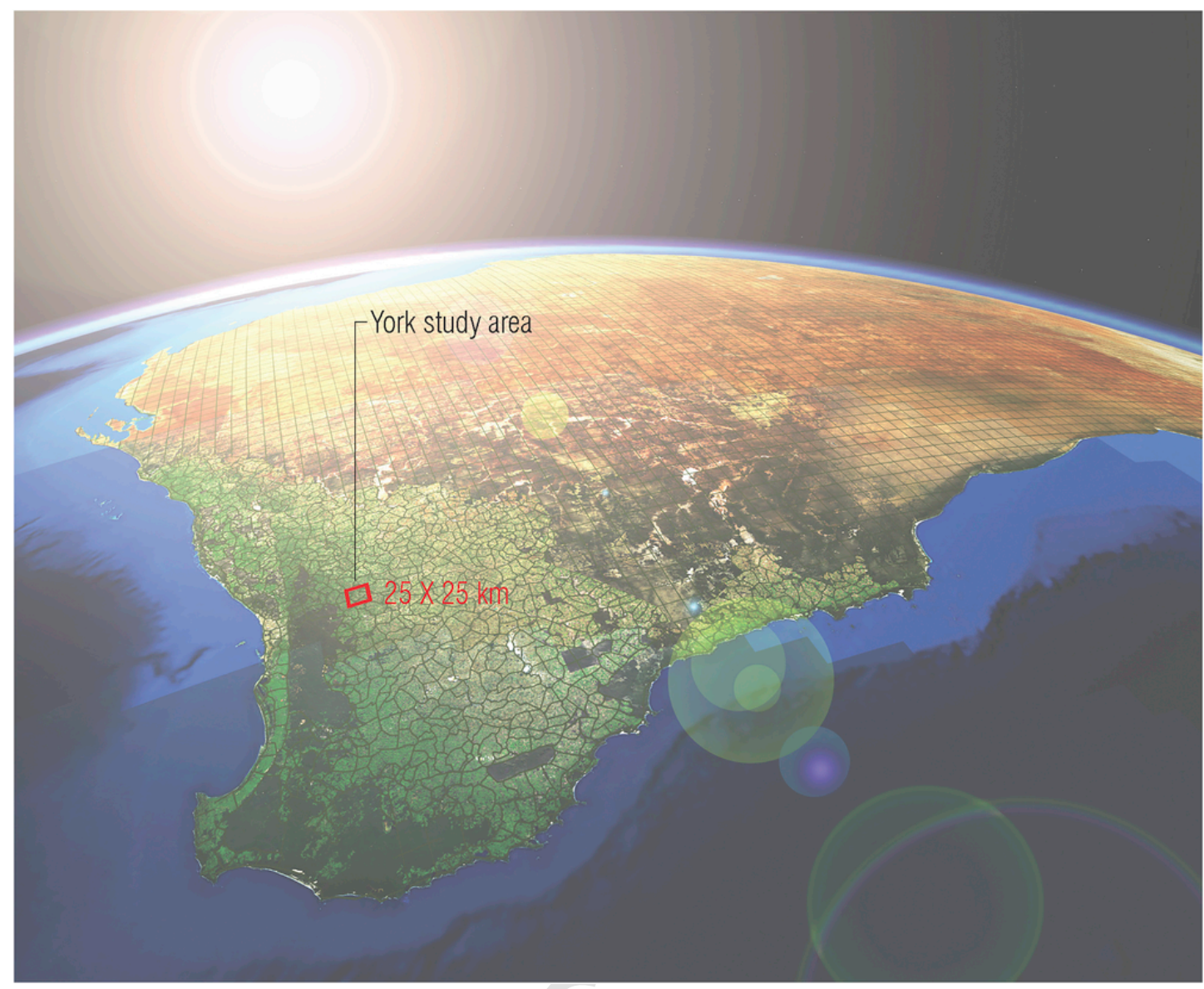

Fig. 1. The ecologically modelled NGN design overlaid over south-western Australia (Kilbane, 2013).

targets (Commonwealth of Australia \& National Reserve System Task Group, 2009).

Secondly, as an example of 'connectivity conservation' the NGN sought to explore and to articulate the principle of ecological connectivity spatially. While the merit of such connectivity is the source of much scholarship and conjecture (Beier \& Noss, 1998; Bennett, 2003; Hobbs, 1992; Hopper, 2009; Margules \& Pressey, 2000; Noss, 1987; Pungetti \& Jongman, 2004; Simberloff, Farr, Cox, \& Mehlman, 1992; Soulé, Terborgh, \& Wildlands Project, 1999; Worboys, Francis, \& Lockwood, 2010), in the Australian context the NGN adopts ecological connectivity as an underlying precautionary principle. This is buoyed by the work of Saunders, Hobbs, and Margules (1991) who suggest that 'we need to take the approach that corridors do have value for biotic movement and attempt to retain a good corridor network wherever possible' (p. 24). Furthermore, Lindenmayer et al. (2010) reinforce the need for ecological connectivity networks at multiple scales through Australia's 'comprehensive, adequate and representative' protected areas system (Natural Resource Management Ministerial Council, 2010). Worldwide, support for connectivity conservation planning has grown, as evidenced by a vast range of initiatives, plans and projects similar to the NGN that exist across a wide range of scales, often referred to as 'ecological' or 'green' networks. Global precedents include the Pan European Ecological Network (PEEN) (Jongman, Bouwma, Griffioen, Jones-Walters, \& Van Doorn, 2011); Florida Greenways (Hauserman, 1995; Hoctor, 2000); Terai Arc Landscape (WWF, 2004); Estonia Ecological Network (Remm, Külvik, Mander, \& Sepp, 2004); the Wildlands Project (Wildlands Network, 2010); and Yellowstone to Yukon (Yellowstone to Yukon Conservation Initiative, 2010). Many Australian connectivity conservation projects also exist (Whitten,
2011; Worboys et al., 2010) and are included within the Australian Government's aspirational policy document the National Wildlife Corridors Plan. These include the Gondwana Link, the Great Eastern Ranges, Habitat 141 and trans-Australia Eco-Links (National Wildlife Corridors Plan Advisory Group, 2012).

Large scale connectivity conservation networks such as these are frequently modelled using GIS, enabling complex spatial investigations into connectivity and ecological distribution across landscapes, regions and continents. Frequently, computations involve the assignment of landscape values, 'weighted models' or circuit theory (Lechner, Doerr, Harris, Doerr, \& Lefroy, 2015; McRae, Dickson, Keitt, \& Shah, 2008). Similarly, the NGN was modelled via a GIS tool, Linkage Mapper (McRae \& Kavanagh, 2011), according to a series of datasets including major hydrological systems, topography and remnant vegetation pattern.

However, while connectivity schemes are now commonplace they are seldom assessed at a fine grain, where the efficacy of their ecological modelling can be questioned. The closest instances of such work can be found in transdisciplinary projects and examples (Nassauer \& Opdam, 2008; Steingröver, Geertsema, \& van Wingerden, 2010; Van Der Windt \& Swart, 2008) where engagement was critical to creating workable designs. This research suggests that ecological modelling is imperfect (only ever as good as the data and process that created it) and that designs for large-scale landscape connectivity should be ground-truthed, that is, to be critically evaluated for their potential. This research posits that without further such assessment and critique - considered by Remm et al. (2004) as the 'expert human dimension' - connectivity conservation planning remains an academic exercise for which three key questions remain: 
- How can connectivity conservation models be reconciled with landscapes replete with existing land-uses?

- How could alternative design visualisations augment potential implementation?

- What spectrum of ecological restoration should be explored in order to secure adoption in target landscapes?

This research introduces a potential method, the design charrette, through which to explore these questions. Individual or collective stakeholders, the ultimate end-users, are rarely considered in the modelling of connectivity conservation; however, charrettes offer them the opportunity to ground-truth the potential of connectivity conservation plans (such as the NGN) across the landscapes they know and are concerned with. Testing and augmenting the precision of modelled connectivity conservation designs in this way allows for the expert human dimension to be integrated through providing the opportunity to assess modelling efficacy, a hands-on method to iteratively improve design accuracy and hence implementation potential. They also offer potential instruction towards improving ecological modelling processes at the outset.

While charrettes are commonly used in architecture and planning (Lennertz, Lutzenhiser, \& National Charrette, 2006) an extensive literature search found no such application of the charrette as a design method within connectivity conservation design and planning. The few instances where similar stakeholder engagement (but not specifically charrettes) has been adopted include examples from Malta (Makhzoumi, 2000), Mexico (Valencia-Sandoval, Flanders, \& Kozak, 2010) and Canada (Lewis \& Sheppard, 2006). Therefore, while this research's merit is exemplified through this Australian exemplar, a method for potential application elsewhere is hereby offered.

\section{Method}

\subsection{Study area and character}

A $25 \times 25 \mathrm{~km}$ site at York in south-western Australia (31 $52^{\prime} 44^{\prime \prime} \mathrm{S}$ $116^{\circ} 45^{\prime} 57^{\prime \prime} \mathrm{E}$ ) established a local study area (Fig. 2) within which to assess a fragment of the continental-scale NGN's potential in detail. York lies within the Wheatbelt of Western Australia, a 140,000 $\mathrm{km}^{2}$ area
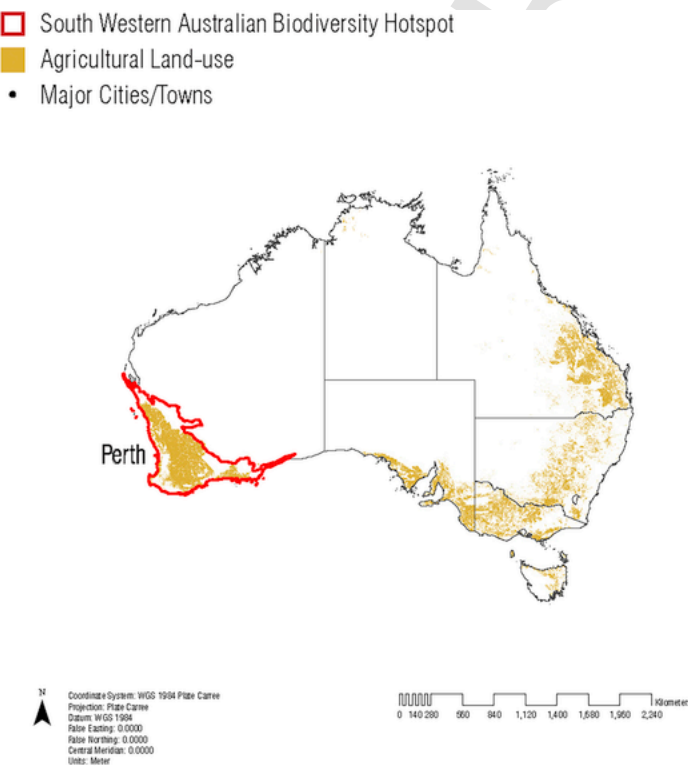

containing the majority of Western Australia's cereal and livestock agriculture, varying in width from 50 to $300 \mathrm{~km}$ and extending some $800 \mathrm{~km}$ from Geraldton in the north to Esperance in the south-east. Noted for its high degree of biological endemism, this ecologically important region (Hobbs, Saunders, \& Arnold, 1993) was cleared of the majority of its native vegetation cover between 1890 and the 1980 s (Bradshaw, 2012; Saunders, 1989). Ongoing processes (Hopper \& Gioia, 2004), including continued land clearing and ecological fragmentation, threaten the decline and extinction of multiple species, and erosion and dryland salinity have led to its nomination as one of only two Australian biodiversity hotspots (Myers, Mittermeier, Mittermeier, da Fonseca, \& Kent, 2000). Dryland salinity, a specific and significant problem in the Western Australian Wheatbelt, affects up to 100,000 ha per year (Hobbs, 1993; Water and Rivers Commission, 2000). The replacement of deep-rooted trees with shallow-rooted perennial crops (Diamond, 2005) causes saline groundwater to rise to the surface with the consequent deposition of salt through evaporation rendering land unusable for agriculture. While fatal to farming, this also impacts many other species, which cannot survive in the new conditions. Secondary ecological impacts to the area's ecology also include introduced species (weeds, rabbits, cats and foxes), altered fire regimes and climate change. In this regard, the Wheatbelt's annual rainfall has decreased $15-20 \%$ in the past 100 years (Indian Ocean Climate Initiative Panel, 2002), threatening not only the potential of the region's biodiversity to adapt (Steffen, 2009) but also the livelihoods of all engaged in primary production (Stokes, 2010).

Predominantly in private ownership, the York study area consists of approximately $75 \%$ active agricultural lands (Western Australian Land Information Authority, 2012) and is punctuated by several small towns within a highly fragmented landscape matrix. The study area contains 8.8\% remnant vegetation land cover (Department of Agriculture and Food Western Australia, 2010) and a meagre 0.11\% protected areas (Department of Sustainability, Environment, Water, Population, Communities, 2012). Counterpoint to this fragmentation, replanting and revegetation efforts - or 'rehabilitation' (Society for Ecological Restoration, 2013) - have been undertaken in the region over past decades (Smith, 2008), although historically their purpose was to address dryland salinity and erosion rather than conservation.

Despite pressing environmental issues and an uncertain future, the Wheatbelt region lacks any co-ordinated spatial overview that could
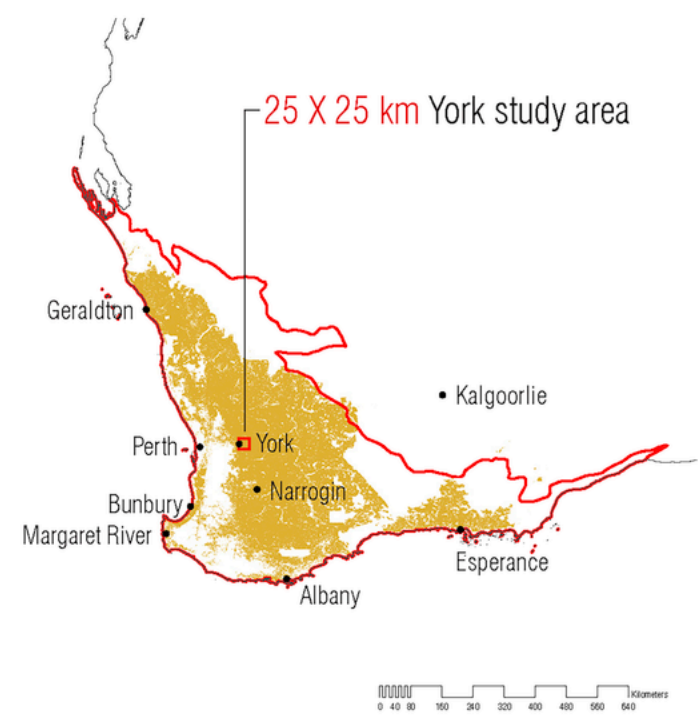

Fig. 2. The $25 \times 25 \mathrm{~km}$ study area located within the south-western Australian biodiversity hotspot (Myers et al., 2000) at York, Western Australia. 
strategically guide the urgently needed ecological restoration efforts. Moreover, such efforts overwhelmingly lack the magnitude required to counteract the steady decline of the region's landscape health: this is estimated as an increase from less than $10 \%$ to a target $40 \%$ vegetative cover across total land area (Hobbs \& Prober, 2008; p. 22). Furthermore, any significant ecological restoration in the York study area faces several challenges. Most importantly, the land is replete with human use and predominantly in private ownership making any restorative actions difficult and requiring significant consultation. In addition, the ecological restoration of these landscapes is notoriously difficult. According to Hopper and Gioia (2004), actions are more akin to 'repair' due to the nutrient deficient OCBIL (Old Climatically Buffered Infertile Landscape) soils. This is compounded by a highly fragmented landscape where few suitable 'reference ecosystem' (Society for Ecological Restoration, 2013) benchmarks exist and their potential as ecological reference points is questioned (Harris, Hobbs, Higgs, \& Aronson, 2006). Further accentuating the challenge to restoration is climate change and consequent shifts to the tolerances, recruitment and home ranges of endemic floral species (Steffen, 2009). This situation, increasingly commonplace worldwide (Zimmermann, Normand, Pearman, \& Psomas, 2013), means that the whole region is better considered through the lens of novel ecosystems, with increasing shifts to new assemblages of species (Higgs, 2003; Hobbs et al., 2006; Hobbs, Higgs, \& Hall, 2013; Hobbs, Higgs, \& Harris, 2009) and ultimately questions ecological restoration objectives and likelihood of success.

\subsection{The design charrette}

Design charrettes have been common in architecture and urban planning disciplines for the last several decades (Lennertz et al., 2006). Condon (2008) defines the design charrette as a time-limited, multiparty design event organized to generate a collaboratively produced plan for a sustainable community' (p. 1). Interdisciplinary in nature, participants are furnished with a range of mapping and spatial information, drawing tools and media such as tracing paper and collectively tackle a specific design problem. The emphasis is upon working in an efficient and productive manner, with the compressed time constraints and liberty to spatially explore ideas and their impacts giving rise to numerous design solutions or scenarios.

The York charrette's aim was to workshop ideas and generate tangible spatial design solutions that could collectively move the NGN from an imprecise modelled framework at the national scale to a spatially accurate and ground-truthed design at the local scale. This provided the opportunity for participants to assess and improve - or ground-truth - the NGN design and its aspirations by considering how such a design could address existing environmental issues and existing landscape and land-use. In so doing, the charrette could provide a blue- print for potential action to ensure the area's ecological health, to reconcile design objectives with existing land-uses and to consider the ecological restoration goals of the network in this contested landscape.

Participation at the charrette was sought from government and community stakeholders familiar with the York area. From a total of 30 invitees, including traditional owners, a total of 15 participants took part in a one-day hands-on workshop. These participants were all familiar with the York area and were either directly or indirectly charged in some respect with the maintenance of a healthy landscape and ecological conditions. They included ecological revegetation staff and natural resource managers, whose key tasks included the distribution of federal funds for the protection of biodiversity via landscape ecological restoration or 'revegetation' efforts, as well as farmers and local government planners. The diverse set of participants and the fluid and iterative charrette method sits in contrast to typical ecological modelling efforts at the local scale, which traditionally rely on further modelling and computation (Lechner et al., 2015; Patru-Stupariu et al., 2015). However, it should be reiterated here that the charrette process was not intended to replace such modelling; instead it was intended to contribute towards more accurate and achievable designs.

The process began with visits to two key locations within the study area, Mount Brown and Mackie River (Fig. 3). The key issues of dryland salinity, ecological fragmentation, and agricultural land-uses were discussed by the group. Furthermore, potential barriers to ecological restoration in this landscape were discussed against the benchmarks set by the Society for Ecological Restoration International (SERI). These include definitions of restoration reference ecosystems and ecological function (Society for Ecological Restoration, 2013).

The group then moved to the York council chambers for the charrette (Fig. 4). Participants were provided with tracing paper and pens and the same range of information that was initially used in the modelling process of the NGN at the continental scale (Fig. 5). This information was provided as a series of 1:50,000 A0 base maps comprising aerial photography, topographic contours, hydrology, roads, cadastre and tenure information (Western Australian Land Information Authority, 2012), soil information (CSIRO, 1991), extant vegetation (Department of Agriculture and Food Western Australia, 2010) and existing protected areas (Commonwealth of Australia, 2010).

The group organisers outlined the origins and aims of the original NGN and discussed the objectives of the redesign process: to assess, to improve accuracy and to augment implementation. In contrast to a connectivity design as a static endpoint, the NGN was offered to the charrette not as a final design but as a point of departure, a flexible framework to be manipulated and adjusted in an iterative manner. The only stipulation given to the group was the maintenance of the two rules that underpinned the original NGN: that structural ecological connectivity was assured and that Aichi targets were met.

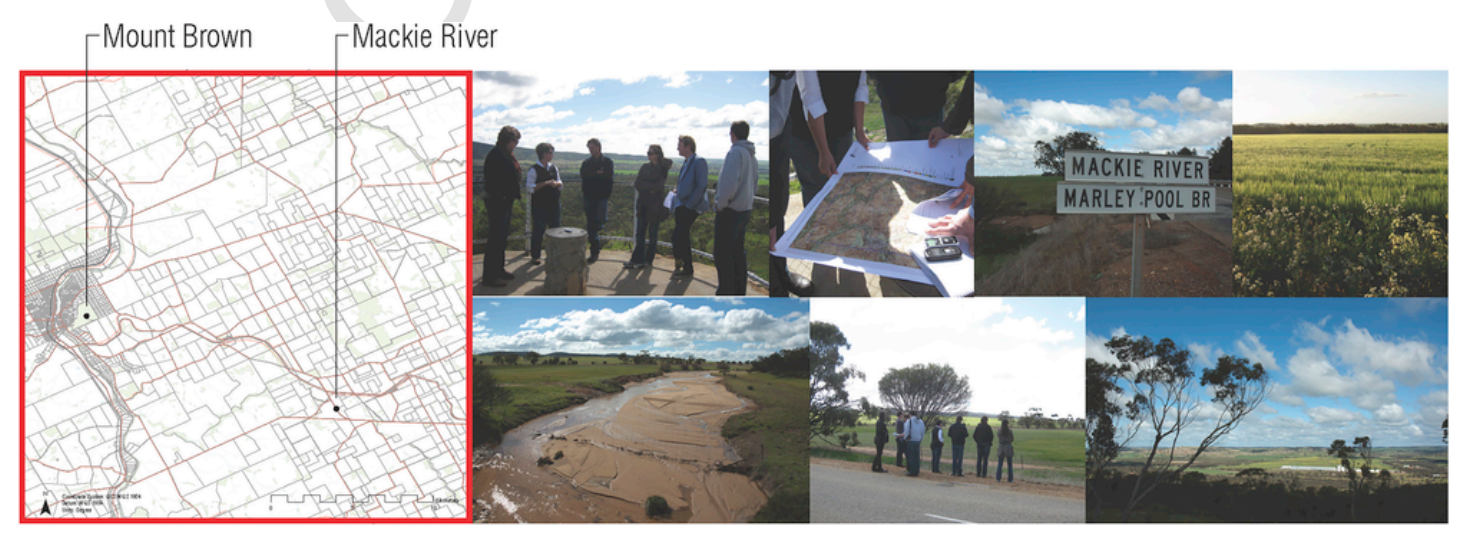

Fig. 3. Visits to two key locations within the study area: Mount Brown ( $\left.31^{\circ} 53^{\prime} 14.79^{\prime \prime} \mathrm{S}, 116^{\circ} 47^{\prime} 4.99^{\prime \prime} \mathrm{E}\right)$ and Mackie River ( $\left.31^{\circ} 55^{\prime} 49.60^{\prime \prime S}, 116^{\circ} 55^{\prime} 16.29^{\prime \prime} \mathrm{E}\right)$. 

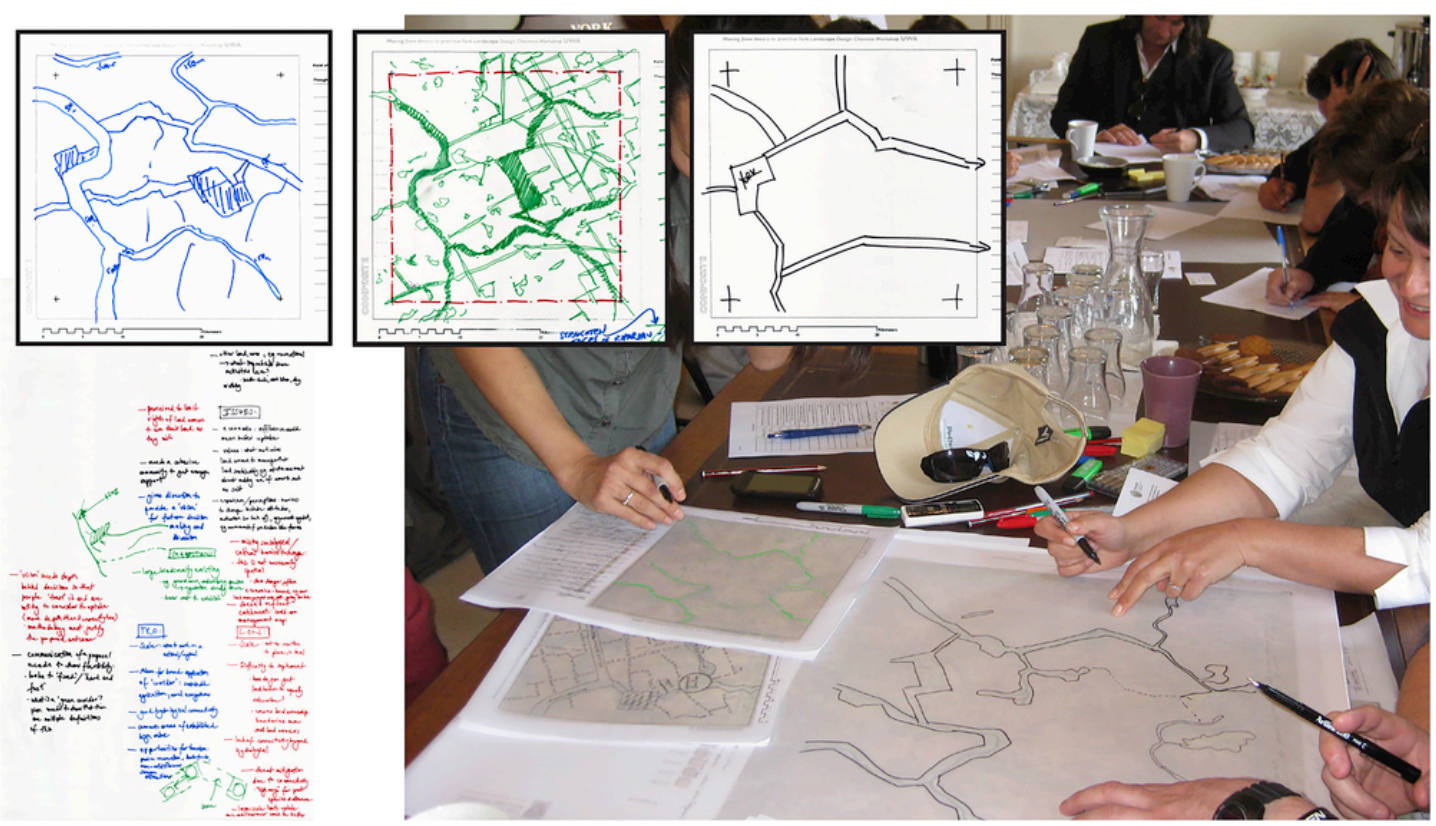

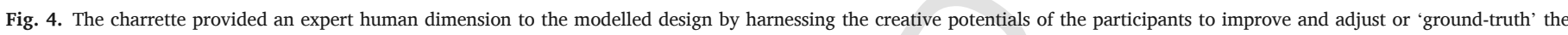
design.
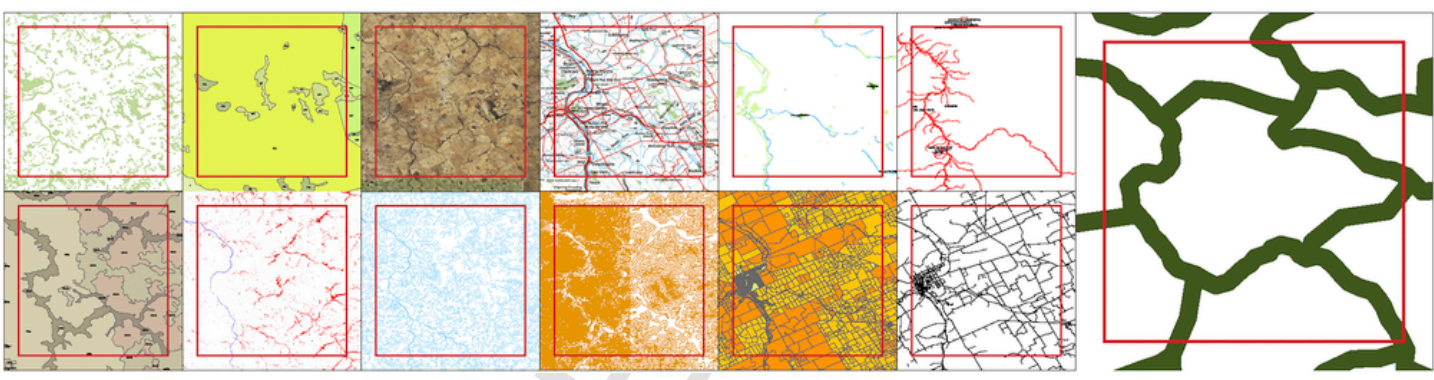

Fig. 5. The original NGN schema, mapping information and aerial photography provided to charrette participants.

\subsection{Redrafting and detailed design to reveal ecological restoration goals}

While the charrette was intended to assess and improve the NGN accuracy through reconfiguration and realignment, the time-limited nature of the charrette meant that a resultant design would still require a further step to achieve precision and visualisation: digitisation through redrafting in AutoCAD (Autodesk Inc, 2011). Secondly, inaccuracies due to tools and limited participant drawing skills were corrected through a careful revision of notes and recorded discussions from the charrette to ensure that the total land impacted by the adjusted NGN met the Aichi target of $17 \%$. Lastly, detailed designs and a suite of visualisations were created to explore spatial impacts and potential ecological restoration trajectories.

\section{Results}

There were three key design outcomes from the charrette and subsequent detailed design stage.

Firstly, the geometry of the NGN was made more precise as the design shifted from ecologically modelled curves and arcs to conform to a rectilinear mosaic of rural landholdings (Fig. 6). A typology of new core areas and connectivity linkages of varying widths and contiguousness better sampled the study area landscape, correlating not only with major landscape features such as rivers valleys, but also sampling ridgelines to encompass and connect a greater spectrum of remnant vegetation across the study area than the original NGN. In figures, the charrette process and subsequent redrafting and design adjustment enabled a reduction of land take from the charrette total of 13,785 ha to 10,594 ha; a reduced number of landholders from over 500-159; and a reduction in future fencing needs from 58 to $30 \mathrm{~km}$. The final land area occupied by the NGN equalled $16.95 \%$ protected area of the total study area of 62,500 ha, approximating the Aichi target of $17 \%$.

Secondly, three functionally distinct design scenarios with varying restoration goals emerged (Fig. 7):

- An 'ecological' or biodiversity-focused ecological restoration scenario with high species diversity and a primary goal of recreating ecological habitat and connectivity to meet SERI benchmarks.

- A 'cultural' or agroforestry scenario with low species diversity and a goal of mitigating salinity through cash-cropping of trees and carbon sequestration.

- A preferred 'hybrid' or multi-functional scenario that balanced elements of both ecological and cultural approaches.

Thirdly, adjusted designs were visualised to demonstrate the impact on the landscape in question. This was conducted initially in sketch form on plans at $1: 50,000$ (A0) during the charrette process, then 


\begin{tabular}{c|c} 
Original NGN & Revised NGN \\
\hline 13,785 hectares affected lands & 10,594 hectares affected lands \\
\hline More than 500 landholders & 159 landholders \\
\hline 58 kilometres of fencing required & 30 kilometres of fencing required \\
\hline $22.05 \%$ of the study area & $16.95 \%$ of the study area
\end{tabular}

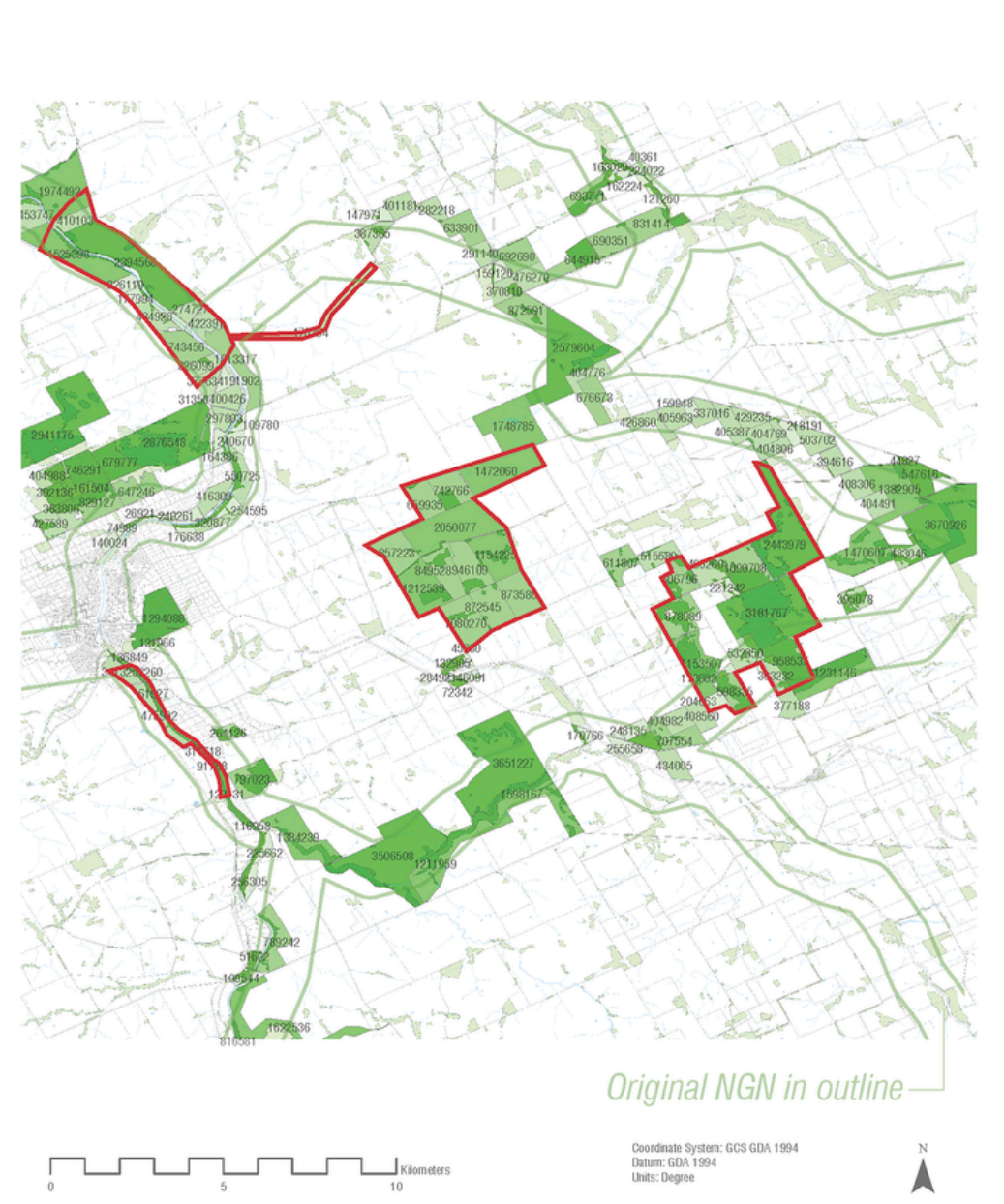

New core areas<smiles>C1C2CC3CC1CC(C2)C3</smiles>

1277 hectares

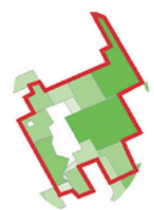

1401 hectares

Linkages or 'corridors'

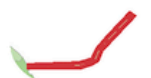

25 metres

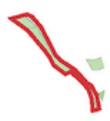

100 metres

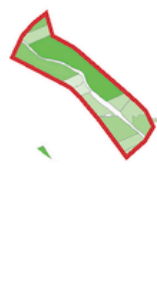

1000 metres

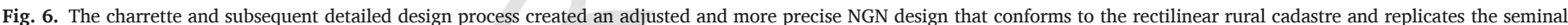
landscape design typology of patch/core areas and network of corridors/linkages.

through subsequent redrafting and detailed design refinement by the landscape architect. The impact on the land area could then be quantified and the achievement of the original protected area target assessed. In addition, computer generated 'before and after' imagery provided perspectives of several key locations within the study area (Fig. 8), which were accompanied by a Google Earth 'kmz' file complete with relevant and spatially accurate encoded geo-spatial information, demonstrating the potential of contemporary technologies to allow exploration of potential spatial and visual impacts.

\section{Discussion}

\subsection{Increased accuracy at the local scale}

The focus of the research was to assess and to reconcile the NGN connectivity conservation design and its ecological policy targets within a complex landscape replete with existing land-uses through a design charrette. Armed with a new set of drawing tools and encour- aged by the novel opportunity to reconsider this landscape afresh, charrette participants embraced the potential of the NGN as a flexible entity, open to iterative readjustment. This created a more precise design, redrafted to better account for landscape specificity as a network of ecological core areas and linkages of various widths and contiguousness. These sampled and reconnected remnant habitat across (and beyond) the study area, replicating a range of the seminal landscape design typology of patch, corridor, and network (Dramstad, Olson \& Forman 1996; Forman \& Godron, 1986).

The charrette and consequent redesign answer the desire expressed by Opdam et al. (2013) to 'develop iterative and collaborative methods for generating solutions', and ground-truthing the NGN design through the charrette and the subsequent detailed design phase delivered the 'expert human dimension' promoted by Remm et al. (2004). The flexibility and open or 'vague' character of the NGN as explored by the charrette was, as suggested by Van Der Windt and Swart (2008, p. 129), 'strong enough to bind and flexible enough to leave room for different operating forms and interpretations' and accommodates the 

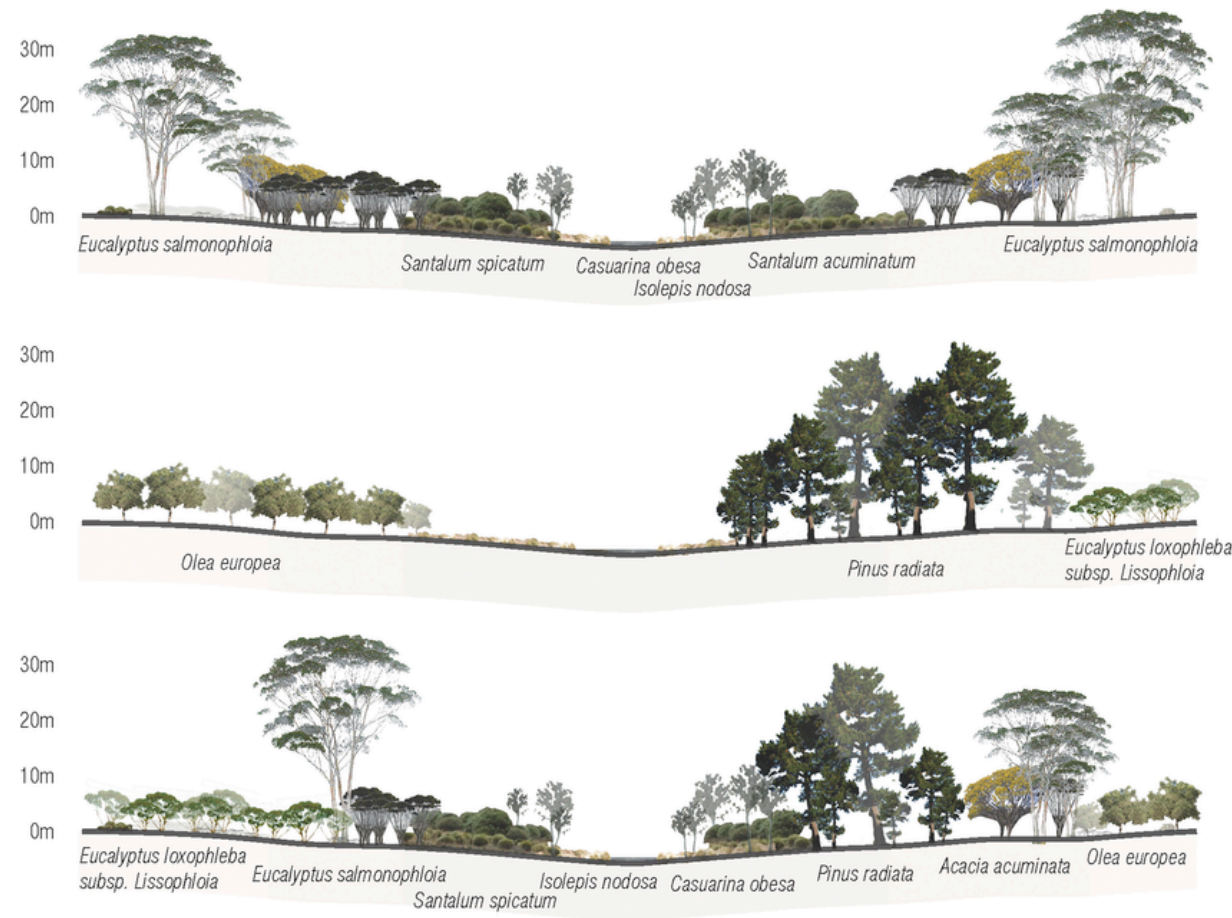

'Ecological'

scenario:

Ecological restoration

with high species

diversity and a primary

goal of recreating

ecological habitat

and connectivity

where absent to SER

benchmarks

'Cultural'

scenario:

Low species diversity

Goal to mitigate salinity through cash cropping agroforestry of trees and carbon sequestration/

oil mallee

Fig. 7. Potential ecological restoration goals and visualisations as scenarios for the adjusted design.

challenge of addressing place-specific landscape issues (Nassauer \& Opdam, 2008). By producing a fine-tuned interconnected protected area network in a timely manner, the research articulated a spatial response to Pungetti and Jongman (2004, p. 146) who ask that 'econets are designed at regional levels, but for implementation an in-depth analysis is required at the local level'.

Critical to the redesign was the adjustment of the geometry of the network to the reality of the existing rural subdivision cadastre. This emerged as the core 'building block' for the refined design, recognised previously by Hobbs (1993) in landscapes with few protected areas candidates (Saunders et al., 1991). The resultant network, ground-truthed by participants' local knowledge, now covered lands already vegetated, fenced and unused by agriculture, yet unprotected. This was acknowledged as an imperfect situation from an ecological point of view as such lands do not necessarily adequately sample the underlying biodiversity; however, working with remnants is frequently the only option available to conservation managers (Saunders et al., 1991). Through this action the number of affected farms was decreased (from more than 500-159) and future implementation foreseeably improved through a reduction in economic impact on fewer landholders. Also of note, the townsite of York was accepted as compatible with the network's aims. The view of participants was that its urban, vegetated character represented substantial habitat, particularly in contrast to the surrounding degraded farmland, which reflects contemporary urban ecological theory (Adams, 2005; Forman, 2008; Tredici, 2010).

While the revised design was adjusted to adhere to the pattern of land subdivision and attempted to address the economic constraints of the landscape in question, this was still merely one possible outcome from a select participant group and prone to errors. Those noted by the authors included the need for further investigation of the questioning of corridor widths (specifically, would they act as ecological sinks) as well as the exclusion of several key existing vegetation patches. The research acknowledges that the redesign process is iterative and as such its repetition could further improve the outcome.
Conversely, the charrette proved useful in assembling detailed local knowledge on species populations that exist on private land in patches too small to be sampled by prior modelling. One example - unavailable from any known spatial data source - included adjusting the design to encompass a rare population of Bronze Orchids (Thelymitra dedmaniarum), which are listed as 'critical' on the Western Australian state register of threatened plants (Government of Western Australia, 2015), and a population of Bettong (Bettongia penicillata), a mammal listed as 'near-threatened' and locally 'vulnerable' by the International Union for Conservation of Nature (IUCN) (Atlas of Living Australia, 2015). Such findings could not have been revealed otherwise, lending credibility to the charrette method.

\subsection{Reframing connectivity conservation and ecological restoration efforts}

While the charrette was successful in adjusting the form of the NGN, it also revealed that it was unrealistic to envisage that land-owners would sacrifice such lands without some form of compensation. To this end, ground-truthing the network with those responsible for ecological restoration activities in the area revealed three possible ecological restoration approaches. These were defined as 'ecological', 'cultural' and the 'hybrid' scenarios. While all three reflected a spectrum of ecological restoration trajectories - and difficulties - within the study area, noting that in this ecologically troubled landscape any form of revegetation could ameliorate landscape health through provision of habitat and connectivity in an otherwise hostile matrix, the charrette preferred the hybrid ecological restoration scenario. This best acknowledged the near-impossibility of restoring such lands due to the high degree of ecological fragmentation, OCBIL soils and lack of suitable ecological restoration references due to climate change while offering a potential economic trade-off. This pragmatic middle ground negotiated a relaxation of SERI ecological restoration benchmarks, meaning that rather than action towards the recreation of a previous ecological baseline, this new design could theoretically offer mutual benefits between biodiversity protection and continued economic return. This approach 


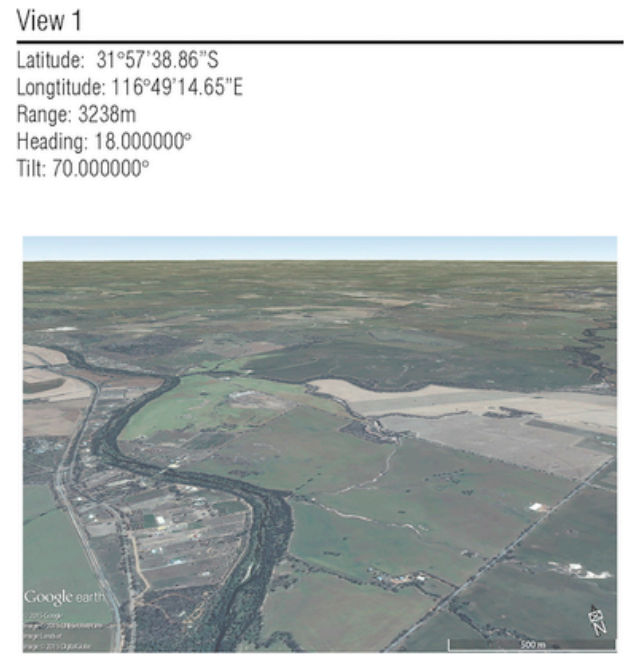

View 2

Latitude: $31^{\circ} 56^{\prime} 29.93^{\prime \prime} \mathrm{S}$

Longtitude: $116^{\circ} 53^{\prime} 29.92^{\prime \prime} \mathrm{E}$

Range: $422 \mathrm{~m}$

Heading: $-3.000000^{\circ}$

Tilt: $69.000000^{\circ}$

Before
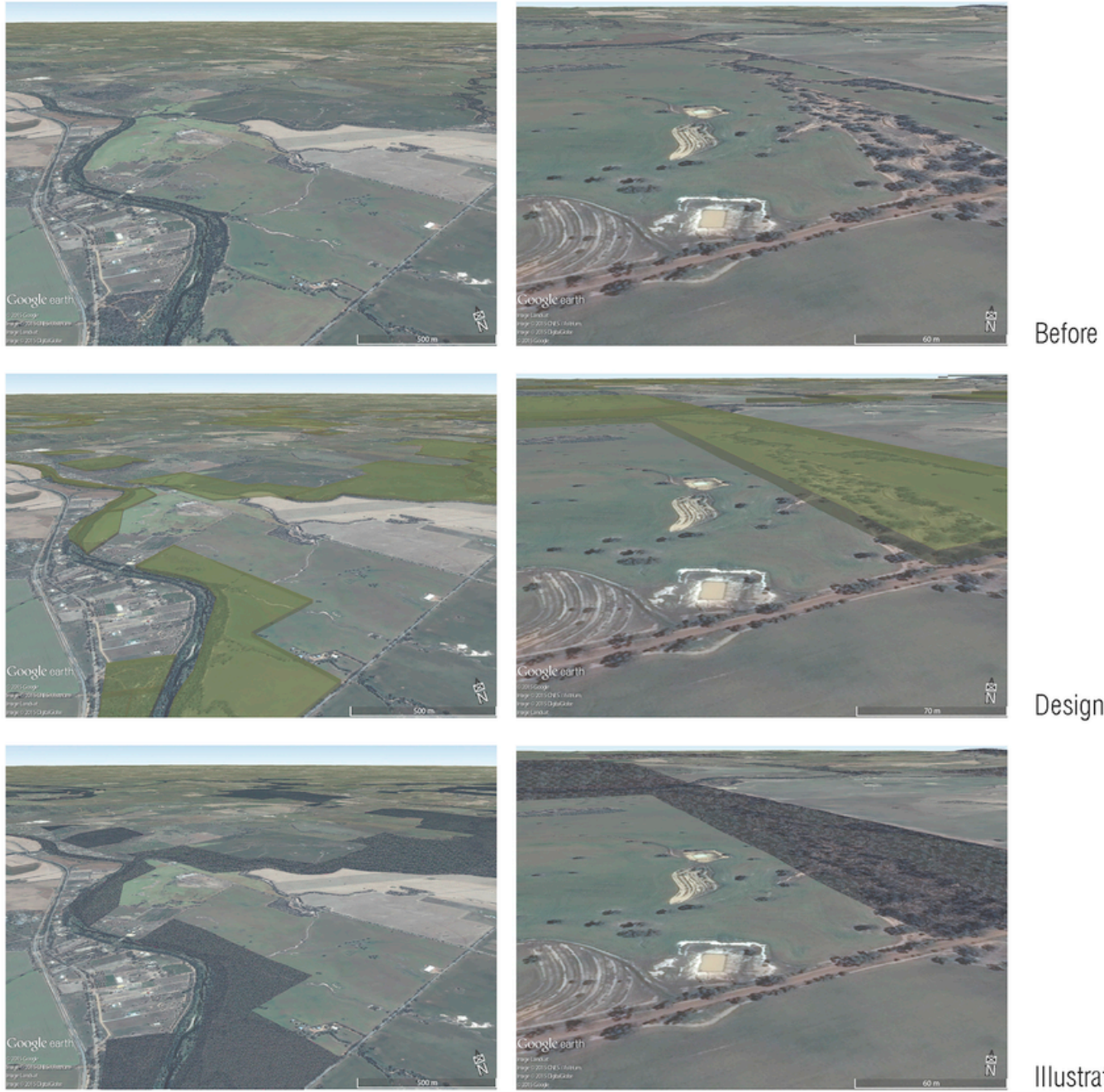

Design overlay

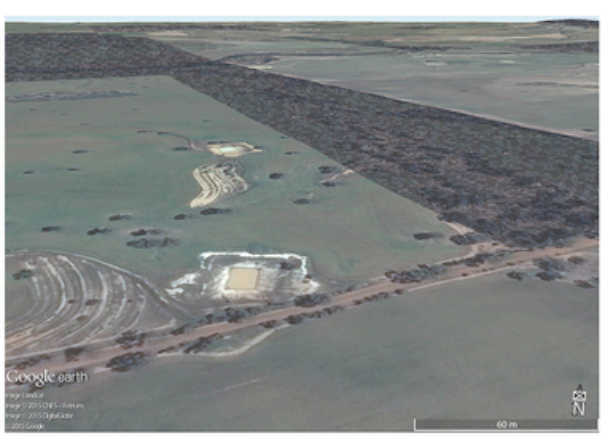

Illustration

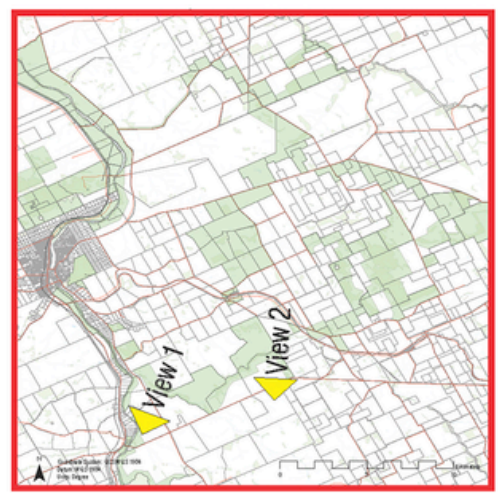

View locations

Fig. 8. Visualisations of the adjusted final design.

could thereby simultaneously assist landscape and ecological health while providing other complementary benefits. This reflects the 'spatial stacking' of functions suggested by Ahern (2012, p. 6) and moves towards a 'synergistic'(European Commission, 2012) and 'multi-functional' (Van Der Windt \& Swart, 2008) approach to landscape planning that embraces a new horizon of ecological restoration possibilities as revegetation - which could include other potentials. For instance, benefits of a hybrid restoration approach across the proposed system extend beyond the protection of the nation's biodiversity to also consider tangible cultural plantings with accompanying ecological bene- 
fits. Specifically, this could include win-win opportunities of agroforestry through cropping of Eucalyptus (Oil Mallee), a profitable form of biofuel tree-cropping using endemic flora that could concurrently re-create ecological connectivity, mitigate salinity and combat erosion, while qualifying for funding through existing government carbon sequestration mechanisms (Australian Government, 2012; Perring et al., 2012). Furthermore, the network could also be interpreted as recreational greenways (Little, 1995) or cultural corridors related to Indigenous culture and to tourism. Finally, the network (through suitable legislation) could be accepted within the IUCN protected area categories as addressed in Lucas (1992) and IUCN (1994), meaning that the original Aichi and NRS targets could be met.

The framing of these research outcomes as green infrastructure (GI) rather than connectivity conservation offers a useful way to view these research outcomes. When considering GI as an 'ecological framework for environmental, social, and economic health' (Benedict \& McMahon, 2006; p. 4), the ecological benefits to this landscape are nested within a broader range of outcomes that may not have otherwise been achieved. It is therefore proposed that GI (and not connectivity conservation) offers a useful avenue to allow a broad exploration of social, economic and even political perspectives, which are so important to consider (Odum, 1986; Opdam et al., 2006) when enacting ecologically focused landscape planning. Furthermore, the GI approach is flexible and allows for novel ecosystem understandings (Higgs, 2003; Hobbs et al., 2009; Hobbs et al., 2013) and subsequent design approaches.

\subsection{Visualisation}

Accurate spatial representation and visualisation of the NGN at all stages of the design process were defining features of this research. Despite the abundance of environmental and ecological data used in ecological modelling and the conceptual modelled outcomes and diagrams that typically accompany many connectivity conservation proposals, detailed imagery illustrating potential landscape impacts and possibilities is still relatively uncommon. This is despite acknowledgement that it is a useful tool in environmental planning communication and decision-making 'simulations' (Nassauer \& Opdam, 2008), which allow for greater transparency and accessibility of ideas (Lewis \& Sheppard, 2006; Valencia-Sandoval et al., 2010).

\subsection{Landscape architecture and connectivity conservation}

This paper posits that Landscape Architecture as a discipline situated within the design professions can make a significant contribution to connectivity conservation planning, fine-tuning and implementation. Here the landscape architect can articulate ecological policy and theory in a spatial sense, exploring the linkage between landscape ecology and design (Nassauer \& Opdam, 2008). Adept at working across scales and across both ecological and cultural paradigms (Deming \& Swaffield, 2011; Weller et al., 2013), through mapping (McHarg, 1969) and through a projective design approach Landscape Architecture is skilled in exploring multiple alternate trajectories (Weller, 2008, 2009). However, most pragmatically, the craft of alternative visuals that have the potential to surpass the schematics (typically in plan view) offered by most ecological modelling proposals is worthy of mention. Instead, accurate impressions of spatial impacts at various scales were offered, not only in plan but also in elevation. Furthermore, the potential to navigate and explore connectivity conservation proposals via mapping software such as Google Earth offers additional engagement benefits (Sheppard \& Cizek, 2009), and while not discussed in this research, visualisation in-situ with appropriately equipped smart phones or other devices is easily achieved.

\section{Conclusion}

This research focused on improving the precision of the NGN, a proposed continental-scale connectivity conservation design within a $25 \times 25 \mathrm{~km}$ study site in rural Western Australia. The original design, derived from connectivity conservation ecological modelling commonplace within the ecological sciences, was imprecise and solely conservation-focused, whereas through the design charrette a more accurate design, adjusted to landscape realities and detached from a nostalgic ecological restoration angle offered a range of ecological and cultural benefits.

In lieu of high fidelity ecological restoration based upon reference ecosystems in a highly disturbed landscape, charrette explorations revealed a suite of options with benefits beyond pure connectivity conservation objectives. A holistic plan - considered as a GI - provided not only a potential blueprint for the long-term survival of the Australian biota, but revealed other possibilities that could help to achieve the project's original ecologically-focused goals. The adjusted and improved design could therefore provide immediate opportunities for degraded rural landscapes to deal with erosion, dryland salinity and water security through the establishment of landscape linkages of differing geometries and structural compositions while enacting Aichi targets and the provision of ecological connectivity. Also, as a system of recreational greenways and cultural corridors related to Indigenous culture and agroforestry this network could additionally sequester carbon and provide further economic benefits.

This research proposes that the success of any ecologically modelled connectivity conservation design lies therefore not in attempts to shoehorn desktop models onto real landscapes, nor in strict adherence to ecological restoration benchmarks, but through flexibility in considering ecological modelling outputs through a subsequent charrette process. By considering models not as an endpoint but rather as a framework open to iterative adjustment through a fluid exploration of design contingencies and ecological restoration objectives, it allows a wider range of potential benefits across both the ecological and cultural and - critically - augmentation of potential implementation with affected stakeholders across these complex landscapes.

While the results include a broad range of ecological restoration possibilities with multiple ecological and cultural benefits specific to the Western Australian example, the authors posit that all connectivity conservation designs could benefit from charrettes as an additional stage of ground-truthing and this methodology is offered as a highly useful planning tool to reconcile connectivity conservation aspirations with complex landscapes in order to create a blueprint for healthier, more resilient landscapes.

\section{Acknoweldgements}

This paper was derived from $\mathrm{PhD}$ research conducted by Simon Kilbane under the supervision of Professor's Hobbs and Weller at the University of Western Australia/University of Pennsylvania.

\section{References}

Adams, L., 2005. Urban wildlife ecology and conservation: A brief history of the discipline. Urban Ecosystems 8 (2), 139-156. http://dx.doi.org/10.1007/s11252-005-4377-7.

Ahern, J., 2012. Urban landscape sustainability and resilience: The promise and challenges of integrating ecology with urban planning and design. Landscape Ecology 1-10. http: //dx.doi.org/10.1007/s10980-012-9799-z.

Atlas of Living Australia, 2015. Bettongia penicillata -Brush tailed bettong. Retrieved 22 August 2015 from http://bie.ala.org.au/species/urn\%3Alsid\%3Abiodiversity.org. au\%3Aafd.taxon\%3Af3063dfe-2f18-4c4f-ade2-3b788895d45a\#

Australian Government, 2012. About the carbon farming initiative. Retrieved 1 November 2012 from http://www.climatechange.gov.au/government/initiatives/ carbon-farming-initiative/about.aspx. 
Autodesk Inc, 2011. AutoCAD ${ }^{\circledR}$ map 3D 2012.

Beier, P., Noss, R.F., 1998. Do habitat corridors provide connectivity?. Conservation Biology 12 (6), 1241-1252.

Benedict, M.A., McMahon, E., 2006. Green infrastructure: Linking landscapes and communities. Island Press, Washington, DC.

Bennett, A.F. (Ed.), 2003. Linkages in the landscape: The role of corridors and connectivity in wildlife conservation, 2nd ed., IUCN, Gland, Switzerland and Cambridge, UK

Bradshaw, C.J.A., 2012. Little left to lose: Deforestation and forest degradation in Australia since European colonization. Journal of Plant Ecology 5 (1), 109-120. http://dx.doi. org/10.1093/jpe/rtr038.

CSIRO, 1991. ASRIS Australian soil resource information system. Retreived from http:// www.asris.csiro.au/themes/Atlas.html.

Commonwealth of Australia \& National Reserve System Task Group, 2009. Australia's strategy for the national reserve system 2009-2030. Commonwealth of Australia, Canberra.

Commonwealth of Australia, 2010. Collaborative Australian protected area database. Retrieved 23 January 2013 from http://www.environment.gov.au/parks/nrs/science/ capad/2010/index.html.

Condon, P.M., 2008. Design charrettes for sustainable communities. Island Press, Washington, DC.

Deming, M.E., Swaffield, S.R., 2011. Landscape architecture research: inquiry, strategy, design. Wiley, Hoboken, N.J.

De-

part-

ment

of

Agri-

cul-

ture

and

Food

West-

ern

Aus-

tralia,

2010 Department of Agriculture and Food Western Australia (Cartographer), Native vegetation current extent - Western Australia, 2010.

Department of Sustainability, Environment, Water, Population, Communities, 2012. from. CAPAD: Protected area data. [Retrieved 29 January 2012] http://www.environment. gov.au/parks/nrs/science/capad.html.

Diamond, J.M., 2005. Collapse: How societies choose to fail or succeed. Viking, New York.

Dramstad, W.E., Olson, J.D., Forman, R.T.T., 1996. Landscape ecology principles in landscape architecture and land-use planning. Harvard University Graduate School of Design, Island Press, American Society of Landscape Architects, Washington, DC.

European Commission, 2012. The multifunctionality of green infrastructure. Retrieved 1 November 2012 from http://ec.europa.eu/environment/nature/ecosystems/docs/ Green_Infrastructure.pdf.

Forman, R.T.T., Godron, M., 1986. Landscape ecology. Wiley, New York.

Forman, R.T.T., 2008. Urban regions: Ecology and planning beyond the city. Cambridge University Press, Cambridge, UK; New York.

Government of Western Australia, 2015. Threatened plants. Retrieved 22 August 2015 from http://www.dpaw.wa.gov.au/plants-and-animals/ threatened-species-and-communities/threatened-plants.

Harris, J.A., Hobbs, R.J., Higgs, E., Aronson, J., 2006. Ecological restoration and global climate change. Restoration Ecology 14 (2), 170-176. http://dx.doi.org/10.1111/j. 1526-100X.2006.00136.x.

Hauserman, J., 1995. Green infrastructure + landscape-architects help design a statewide greenway network in Florida. Landscape Architecture 85 (7), 58-61.

Higgs, E.S., 2003. Nature by design: People, natural process, and ecological design. MIT Press, Cambridge, Mass.

Hobbs, R.J., Prober, S.M., 2008. Temperate eucalypt woodlands. In: Lindenmayer, D., Publishing, C. (Eds.), Ten commitments: Reshaping the lucky country's environment. CSIRO Pub, Collingwood, Vic.

Hobbs, R.J., Saunders, D.A., Arnold, G.W., 1993. Integrated landscape ecology: A western australian perspective. Biological Conservation 64 (3), 231-238.

Hobbs, R.J., Arico, S., Aronson, J., Baron, J.S., Bridgewater, P., Cramer, V.A., ... Zobel, M., 2006. Novel ecosystems: Theoretical and management aspects of the new ecological world order. Global Ecology and Biogeography 15 (1), 1-7. http://dx.doi.org/10. 1111/j.1466-822X.2006.00212.x.

Hobbs, R.J., Higgs, E., Harris, J.A., 2009. Novel ecosystems: Implications for conservation and restoration. Trends in Ecology \& Evolution 24 (11), 599-605. http://dx.doi.org/ 10.1016/j.tree.2009.05.012.

Hobbs, R.J., Higgs, E., Hall, C., 2013. Novel ecosystems: Intervening in the new ecological world order. Wiley-Blackwell, Hoboken, N.J.

Hobbs, R.J., 1992. The role of corridors in conservation: Solution or bandwagon?. Trends in Ecology \& Evolution 7 (11), 389-392.

Hobbs, R.J., 1993. Effects of landscape fragmentation on ecosystem processes in the Western Australian wheatbelt. Biological Conservation 64 (3), 193-201. http://dx.doi.org/ 10.1016/0006-3207(93)90321-q.

Hoctor, T., 2000. Identifying a linked reserve system using a regional landscape approach: The Florida ecological network. Conservation Biology 14 (4), 984-1000.
Hopper, S., Gioia, P., 2004. The south-west Australian floristic region: Evolution and conservation of a global hot spot of biodiversity. Annual Review of Ecology Evolution and Systematics 35, 623-650.

Hopper, S.D., 2009. OCBIL theory: Towards an integrated understanding of the evolution, ecology and conservation of biodiversity on old, climatically buffered, infertile landscapes. Plant and Soil 322 (1-2), 1-2.

International Union for Conservation of Nature (IUCN), 1994. Guidelines for protected area management categories. IUCN, Cambridge, UK.

Indian Ocean Climate Initiative Panel, 2002. Climate variability and change in south west Western Australia. Department of Environment, East Perth, W.A.

Jongman, R., Bouwma, I., Griffioen, A., Jones-Walters, L., Van Doorn, A., 2011. The pan European ecological network: PEEN. Landscape Ecology 26 (3), 311-326. http://dx. doi.org/10.1007/s10980-010-9567-x.

Kilbane, S., 2013. Green infrastructure: Planning a national green network for Australia. Journal of Landscape Architecture 8 (1), 64-73. http://dx.doi.org/10.1080/ 18626033.2013.798930.

Lechner, A.M., Doerr, V., Harris, R.M.B., Doerr, E., Lefroy, E.C., 2015. A framework for incorporating fine-scale dispersal behaviour into biodiversity conservation planning. Landscape and Urban Planning 141, 11-23.

Lennertz, W.R., Lutzenhiser, A., National Charrette Institute, 2006. The charrette handbook: The essential guide for accelerated, collaborative community planning. American Planning Association, Chicago, Ill.; Washington, D.C.

Lewis, J.L., Sheppard, S.R.J., 2006. Culture and communication: Can landscape visualization improve forest management consultation with Indigenous communities?. Landscape and Urban Planning 77 (3), 291-313. http://dx.doi.org/10.1016/j.landurbplan. 2005.04.004.

Lindenmayer, D.B., Steffen, W., Burbidge, A.A., Hughes, L., Kitching, R.L., Musgrave, W., ... Werner, P.A., 2010. Conservation strategies in response to rapid climate change: Australia as a case study. Biological Conservation 143 (7), 1587-1593. http://dx.doi. org/10.1016/j.biocon.2010.04.014.

Little, C.E., 1995. In: Paperbacks, J.H. (Ed.), Greenways for America/Charles E. Little. Johns Hopkins University Press, Baltimore.

Lucas, P.H.C., 1992. Protected landscapes: A guide for policy-makers and planners. Chapman \& Hall, London; New York.

Makhzoumi, J., 2000. Landscape ecology as a foundation for landscape architecture: Application in Malta. Landscape and Urban Planning 50 (1-3), 167-177. http://dx. doi.org/10.1016/S0169-2046(00)00088-8.

Margules, C.R., Pressey, R.L., 2000. Systematic conservation planning. Nature 405 (6783), 243-253.

McHarg, I.L., 1969. Design with nature [by] Ian L. McHarg. Published for the American Museum of Natural History [by] the Natural History Press, Garden City, N.Y.

McRae, B.H., Kavanagh, D.M., 2011. Linkage mapper connectivity analysis software The Nature Conservancy, Seattle WA. Retrieved 1 January 2012 from http://www. circuitscape.org/linkagemapper.

McRae, B.H., Dickson, B.G., Keitt, T.H., Shah, V.B., 2008. Using circuit theory to model connectivity in ecology, evolution, and conservation. Ecology 89 (10), 2712-2724.

Myers, N., Mittermeier, R.A., Mittermeier, C.G., da Fonseca, G.A.B., Kent, J., 2000. Biodiversity hotspots for conservation priorities. Nature 403 (6772), 853-858. http:// www.nature.com/nature/journal/v403/n6772/suppinfo/403853a0_S1.html.

Nassauer, J.I., Opdam, P., 2008. Design in science: Extending the landscape ecology paradigm. Landscape Ecology 23 (6), 633-644.

National Wildlife Corridors Plan Advisory Group, 2012. National wildlife corridors plan. Australian Government.

Natural Resource Management Ministerial Council, 2010. Australia's biodiversity conservation strategy 2010-2030. Department of Sustainability, Environment, Water, Population and Communities, Canberra.

Noss, R.F., 1987. Corridors in real landscapes: A reply to Simberloff and Cox. Conservation Biology 1 (2), 159-164.

Odum, E.P., 1986. Introductory review: Perspective of ecosystem theory and application. In: Polunin, N. (Ed.), Ecosystem theory and application. Wiley, New York, pp. 1-11.

Opdam, P., Steingröver, E., Van Rooij, S., 2006. Ecological networks: A spatial concept for multi-actor planning of sustainable landscapes. Landscape and Urban Planning 75 (3), 322-332.

Opdam, P., Nassauer, J., Wang, Z., Albert, C., Bentrup, G., Castella, J.C., ... Swaffield, S., 2013. Science for action at the local landscape scale. Landscape Ecology 28 (8), 1439-1445. http://dx.doi.org/10.1007/s10980-013-9925-6.

Patru-Stupariu, I., Stupariu, M.S., Tudor, C.A., Kienast, F., Hersperger, A.M., ... Gavrilidis, A., 2015. Landscape fragmentation in Romania's Southern Carpathians: Testing a European assessment with local data. Landscape and Urban Planning 143, 1-8.

Perring, M.P., Standish, R.J., Hulvey, K.B., Lach, L., Morald, T.K., Parsons, R., Hobbs, R.J., 2012. The Ridgefield multiple ecosystem services experiment: Can restoration of former agricultural land achieve multiple outcomes?. Agriculture, Ecosystems and Environment 163, 14-27. http://dx.doi.org/10.1016/j.agee.2012.02.016.

Pungetti, G., Jongman, R.H., 2004. Ecological networks and greenways: Concept, design implementation. Cambridge University Press, New York.

Remm, K., Külvik, M., Mander, , Sepp, K., 2004. Design of the Pan-European ecological network: A national level attempt. In: Jongman, R.H.G., Pungetti, G. (Eds.), Ecological networks and greenways. Cambridge University Press.

Saunders, D.A., Hobbs, R.J., Margules, C.R., 1991. Biological consequences of ecosystem fragmentation: A review. Conservation Biology 5 (1), 18-32.

Saunders, D.A., 1989. Changes in the Avifauna of a region, district and remnant as a result of fragmentation of native vegetation: The Wheatbelt of Western Australia. A 
case study. Biological Conservation 50 (1), 99-135. http://dx.doi.org/10.1016/ 0006-3207(89)90007-4.

Sheppard, S.R.J., Cizek, P., 2009. The ethics of Google Earth: Crossing thresholds from spatial data to landscape visualisation. Journal of Environmental Management 90 (6), 2102-2117. http://dx.doi.org/10.1016/j.jenvman.2007.09.012.

Simberloff, D., Farr, J.A., Cox, J., Mehlman, D.W., 1992. Movement corridors: Conservation bargains or poor investments?. Conservation Biology 6 (4), 493-504.

Smith, F.P., 2008. Who's planting what, where and why - and who's paying? An analysis of farmland revegetation in the central Wheatbelt of Western Australia. Landscape and Urban Planning 86 (1), 66-78. http://dx.doi.org/10.1016/j.landurbplan. 2007.12.008

Society for Ecological Restoration, 2013. Restoration primer. Retrieved 1 November 2013 from http://www.ser.org/resources/resources-detail-view/ ser-international-primer-on-ecological-restoration\#3.

Soulé, M.E., Terborgh, J., Wildlands Project, 1999. Continental conservation: Scientific foundations of regional reserve networks. Island Press, Washington, D.C.

Steffen, W., 2009. Australia's biodiversity and climate change. CSIRO Publishing, Collingwood, Victoria.

Steingröver, E., Geertsema, W., van Wingerden, W.R.E., 2010. Designing agricultural landscapes for natural pest control: A transdisciplinary approach in the Hoeksche Waard (The Netherlands). Landscape Ecology 25 (6), 825-838. http://dx.doi.org/10.1007/ s10980-010-9489-7.

Stokes, C., 2010. Adapting agriculture to climate change: Preparing Australian agriculture, forestry and fisheries for the future. CSIRO Publishing, Collingwood, Vic.

Tredici, P.D., 2010. Spontaneous urban vegetation: Reflections of change in a globalized world. Nature Cult. Nature and Culture 5 (3), 299-315.

United Nations, 2010. TARGET 11?Technical rationale extended (provided in document COP/10/INF/12/Rev.1). Retrieved 30 January 2014 from https://www.cbd.int/sp/ targets/rationale/target-11/.

United Nations, 2010. Tenth meeting of the conference of the parties to the convention on biological diversity (COP 10): Meeting documents. Retrieved 30 January 2012 from http://www.cbd.int/doc/meetings/cop/cop-10/official/cop-10-27-en.pdf.

Valencia-Sandoval, C., Flanders, D.N., Kozak, R.A., 2010. Participatory landscape planning and sustainable community development: Methodological observations from a case study in rural Mexico. Landscape and Urban Planning 48 (1), 63
Van Der Windt, H.J., Swart, J.A.A., 2008. Ecological corridors, connecting science and politics: The case of the Green River in the Netherlands. Journal of Applied Ecology 45 (1), 124-132. http://dx.doi.org/10.1111/j.1365-2664.2007.01404.x.

WWF, 2004. The terai arc landscape -Bengal tigers in the himalayas' shadow: WWF. Retrieved 30 January 2014 from http://tigers.missouri.edu/files/Terai_Arc2004.pdf.

Water and Rivers Commission, 2000. Water facts 15. (0-7309-7468-5). east perth: Government of western Australia. 5-7468. Retrieved 30 January 2014 from www.water.wa. gov.au/PublicationStore/11470.pdf.

Weller, R., Kilbane, S., Neldner, J., Padgett, S.P., Siero, G., 2013. Asking difficult questions: The importance and potential of landscape architectural design research in exploring answers to complex questions. In: Li, M.H., Kim, H.W. (Eds.), CELA 2013: Space and time, place and duration. Conference Proceedings, Council of Educators in Landscape Architecture Austin, Texas.

Weller, R., 2008. Planning by design: Landscape architectural scenarios for a rapidly growing city. Journal of Landscape Architecture 3 (2), 18-29.

Weller, R., 2009. Boomtown 2050: Scenarios for a rapidly growing city. UWA Publishing, Crawley. Western Australia.

Western Australian Land Information Authority, 2012. Map reproduced by permission of the Western Australian land information authority, P507/2012. Landgate, WA.

Whitten, S., 2011. A compendium of existing and planned Australian wildlife corridor projects and initiatives, and case study analysis of operational experience: A report for the Australian Government Department of Sustainability, Environment, Water, Population and Communities. CSIRO, Canberra, A.C.T.

Wildlands Network, 2010. Home page - Wildlands network - Formerly wildlands project. Retrieved 1 February 2010 from http://wildlandsproject.org/cms/page1000. $\mathrm{cfm}$.

Worboys, G., Francis, W.L., Lockwood, M., 2010. Connectivity conservation management: A global guide. Earthscan, London; Sterling, VA.

Yellowstone to Yukon Conservation Initiative, 2010. Yellowstone to Yukon: A blueprint for wildlife conservation. Retrieved 1 December 2014 from http://y2y.net.

Zimmermann, N.E., Normand, S., Pearman, P.B., Psomas, A., 2013. Future ranges in European tree species. In: Fitzgerald, J., Lindner, M. (Eds.), Adapting to climate change in European forests - Results of the MOTIVE project. Pensoft, Sofia. 